\title{
The pregnancy-associated spontaneous coronary artery dissection in a young woman with a novel missense mutation in NOTCH1: a case report
}

\author{
Bo Bai ${ }^{\dagger}$, Meng Zhang ${ }^{\dagger}$, Yihao Zhuang, Jirong Zhu, Wenjing Li, Wei Ma and Haibo Chen ${ }^{*}$ (D)
}

\begin{abstract}
Background: Spontaneous coronary artery dissection (SCAD) is frequently reported as a disorder that primarily affects women without risk factors for cardiovascular disease. Although it has been recognized as one of the genetically mediated vascular disorders, the genetic pathogenesis of SCAD remains obscure to date.

Case presentation: In this report, we presented a rare case of pregnancy-associated SCAD in a young woman that occurred in multiple coronary arteries within a short period. The initial conservative management and then intravascular ultrasound-guided primary percutaneous coronary intervention (PCI) were adopted to achieve optimal results of revascularization in affected coronary arteries and avoid potential risks for $\mathrm{PCl}$-associated complications. We further performed the whole-exome sequencing and Sanger sequencing and, for the first time, reported a novel heterozygous missense variant, c.4574 C > T (p.Arg1438Cys), in the NOTCH1 gene. This variant has never been documented in the medical literature and was predicted as being potentially damaging or disease-causing variant.

Conclusions: We described a rare case of recurrent SCAD in a young woman after baby delivery. The initial conservative management and $\mathrm{PCl}$ with multiple stent implantations were successfully implemented to achieve optimal results of revascularization in coronary arteries. We, for the first time, identified a novel missense variant in the NOTCH1 gene, which appears to be a potential predisposing factor for artery fragility.
\end{abstract}

Keywords: Spontaneous coronary artery dissection, NOTCH 1 variant, Myocardial infarction, Primary percutaneous coronary intervention, Pregnancy

\section{Background}

Spontaneous coronary artery dissection (SCAD) is defined as an epicardial coronary artery dissection that is not associated with atherosclerosis or trauma and not iatrogenic [1]. It has been deemed rare historically and frequently reported in young women with pregnancy or within the peripartum period $[2,3]$. Despite a relatively

\footnotetext{
* Correspondence: chb1401HF@gmail.com

${ }^{+}$Bo Bai and Meng Zhang contributed equally to this work

Department of Cardiology, Shenzhen Second People's Hospital, the First Affiliated Hospital of Shenzhen University Health Science Center, No. 3002, Sungang West Road, Futian District, Shenzhen 518035, China
}

low incidence of pregnancy-associated SCAD, pregnant women with SCAD seem to have more acute presentations and poorer prognosis, compared to women with SCAD unrelated to pregnancy [2-4]. The majority of patients experienced acute ST-elevation myocardial infarction (STEMI), cardiogenic shock, cardiac arrest, and maternal death [2-4]. However, the precise nature of this association remains to be elucidated. It is likely to be driven by multiple predisposing factors, such as underlying arteriopathies, genetic factors, hormonal

(c) The Author(s). 2020 Open Access This article is licensed under a Creative Commons Attribution 4.0 International License, which permits use, sharing, adaptation, distribution and reproduction in any medium or format, as long as you give appropriate credit to the original author(s) and the source, provide a link to the Creative Commons licence, and indicate if changes were made. The images or other third party material in this article are included in the article's Creative Commons licence, unless indicated otherwise in a credit line to the material. If material is not included in the article's Creative Commons licence and your intended use is not permitted by statutory regulation or exceeds the permitted use, you will need to obtain permission directly from the copyright holder. To view a copy of this licence, visit http://creativecommons.org/licenses/by/4.0/. The Creative Commons Public Domain Dedication waiver (http://creativecommons.org/publicdomain/zero/1.0/) applies to the data made available in this article, unless otherwise stated in a credit line to the data. 
influences, inherited or acquired arteriopathies, or yetundefined mechanisms $[1,5,6]$.

The cohort studies and case reports have provided suggestive findings that SCAD is one of the genetically mediated vascular disorders. Mutation in many genes that are related to arterial fragility and dissections have been reported in SCAD cases, including variations in TSR1, FBN1, ACTA2, SMAD3, COL3A1, TGFBR1/R2 [6-9]. Due to insufficient cases discovered, the genetics of SCAD remains obscure to date. Identification of potential risk loci will broaden our knowledge of SCAD pathogenesis as well as diagnosis, treatment, and prognosis.

\section{Case presentation}

A 30-year-old woman suffered from sustained chest pain in the early postpartum period ( $15 \mathrm{~h}$ after vaginal delivery). She had no history of hypertension, diabetes, and smoking. The electrocardiogram (ECG) demonstrated the upsloping ST-segmental depression in precordial leads and positive symmetric $\mathrm{T}$ waves, indicating the de
Winter syndrome, a condition associated with acute occlusion of the left anterior descending coronary artery (LAD) (Fig. 1) [10]. Twenty minutes later, the ECG showed the typical ST-segment elevation in leads V1 to V4 (Fig. 1). She was administrated with $300 \mathrm{mg}$ aspirin and immediately transferred to our hospital. The repeated ECG indicated the tombstoning ST-segment elevation in leads V2 and V3 (Fig. 1) [11]. The laboratory results showed hs-troponin I of $0.46 \mathrm{ng} / \mathrm{mL}$ (normal range $<0.02 \mathrm{ng} / \mathrm{mL}$ ) and CK-MB of $24 \mathrm{ng} / \mathrm{mL}$ (normal range $<7.2 \mathrm{ng} / \mathrm{mL}$ ), supporting a diagnosis of the STEMI. Echocardiography demonstrated unsynchronized left ventricular wall motion but normal systolic function $(\mathrm{EF}=64 \%)$. After administration with $180 \mathrm{mg}$ ticagrelor, the timely primary percutaneous coronary intervention (PCI) was implemented to this patient. Coronary angiogram revealed the presence of long diffuse stenosis from ostium to distal end of LAD with Thrombolysis in Myocardial Infarction (TIMI) flow 3. We noticed the contrast hold-up near to mid-segments of LAD and considered which was likely attributable to SCAD,

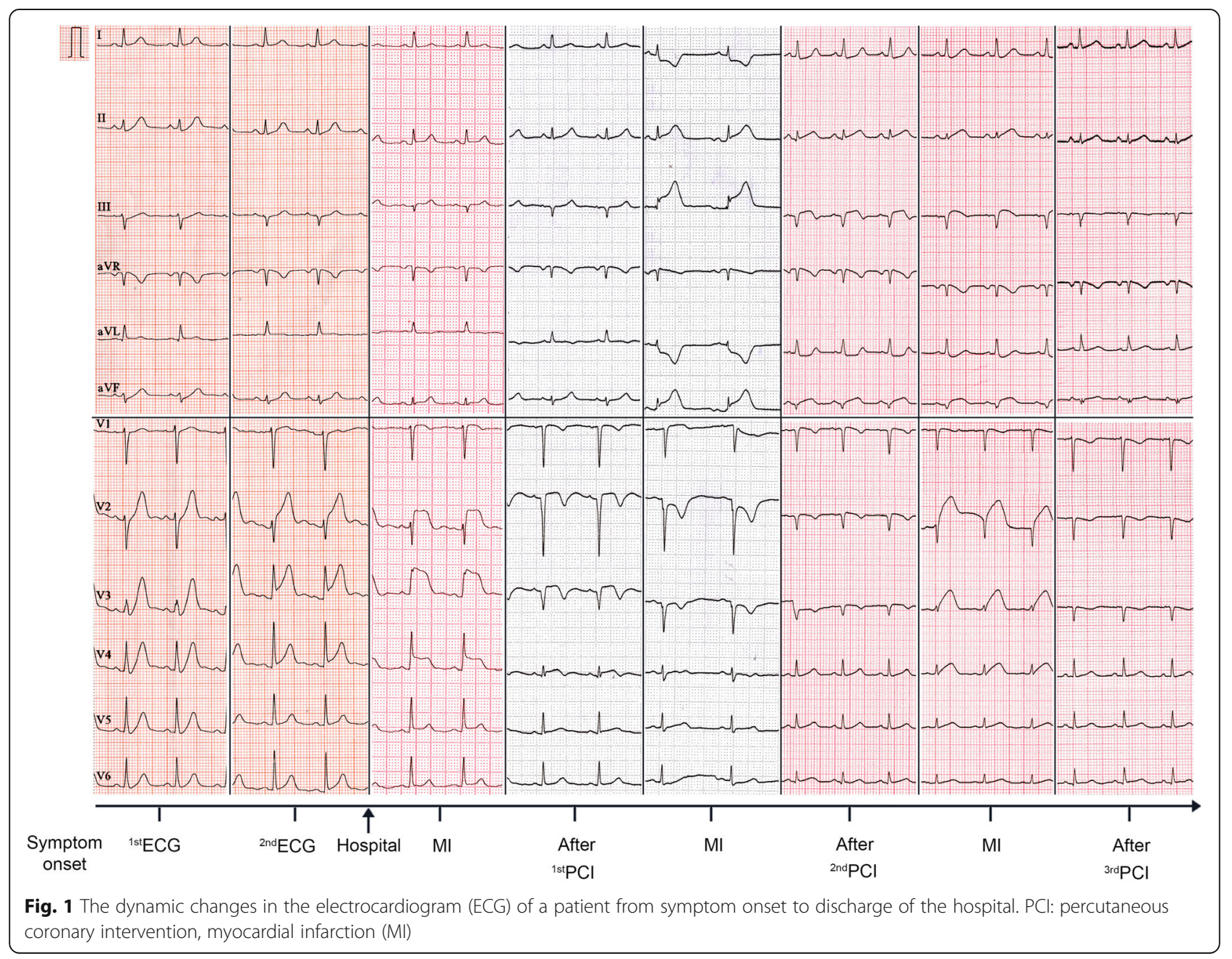


coronary vasculitis, or intramural hematoma (IMH) (Fig. 2a). A Run-through NS Extra Floppy guidewire was used to cross LAD to the distal end. Sprinter balloon was then positioned at proximal-middle LAD, and undersized balloons at low-pressure dilatation were performed to achieve a good angiographic result (Fig. 2b). After PCI, she did not complain about any discomfort, and the chest pain was substantially relieved. The ECG showed sinus rhythm and the disappearance of STsegment elevation (Fig. 1). The dual-antiplatelet and antithrombotic therapies were then carried on by administration of aspirin (100 mg/day), clopidogrel $(75 \mathrm{mg} /$ day), and subcutaneous low molecular weight heparin (0.4 $\mathrm{mL}$, twice per day). During the following 2 days, she had no chest discomfort. Three days after the initial PCI, she re-experienced intense chest pain and sweating. The
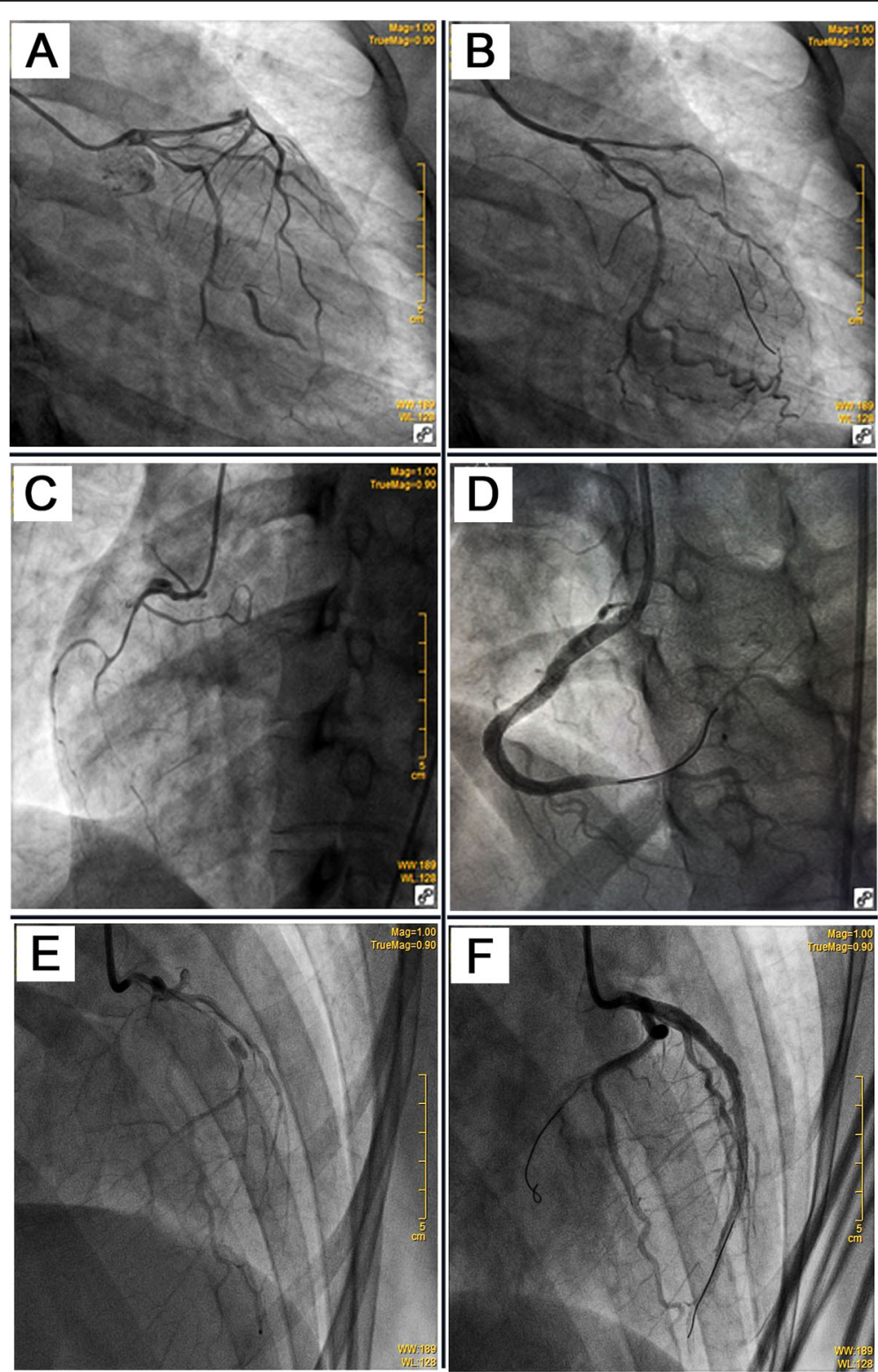

Fig. 2 a Left coronary angiogram showed long diffuse stenosis in LAD and LCX. b The TIMI 3 flow was restored in distal LAD after dilatation with undersized balloons at low-pressure. c Three days after the initial PCl, the Ml recurred in this patient. The angiography showed coronary dissection in the ostium of the right coronary artery with TIMI1 flow 1. d No residual stenosis was achieved after implantation with multiple drugeluting stents from distal to proximal segments of the right coronary artery. e Three days later, the patient suffered from Ml again. Coronary angiogram demonstrated long diffuse stenosis in LAD and LCX with TIMI flow 3. f Multiple drug-eluting stents were implanted into focal lesions of LAD, LCX, and LMC arteries to seal intimal tears and achieve the optimal results of no residual stenosis and restoration of TIMI 3 flow. LAD: left anterior descending coronary artery; LCX: left circumflex coronary artery; LMC: left main coronary artery; TIMI: Thrombolysis in Myocardial Infarction 
ECG indicated ST-segment elevation in leads II, III, and AVF (Fig. 1), indicating acute MI in the inferior wall and right ventricle. After administration with $300 \mathrm{mg}$ aspirin and $300 \mathrm{mg}$ clopidogrel, she underwent the PCI immediately. Coronary angiogram demonstrated the SCAD in the ostium of the right coronary artery (RCA) with TIMI flow 1 (Fig. 2c). A Run-through NS Extra Floppy guidewire was used to cross RCA to the distal end. The intravascular ultrasound (IVUS) ascertained the guidewire passed through the true lumen properly and showed the artery dissection starting from proximal RCA. The IMH in the mid-to-distal segments compressed the true lumen (Fig. 3a, left and right). After pre-dilations by
Sprinter balloon at proximal-to-mid RCA, the multiple drug-eluting stents were implanted sequentially from distal to proximal segments and the ostium of RCA to restore TIMI flow 3 with no residual stenosis (Fig. 2d). IVUS showed stents attached to endothelium well and covered artery dissections completely (Fig. 3b, left and right). After PCI, the patient did not complain about chest pain and had a normal cardiac function $(\mathrm{EF}=$ 64\%). The ECG indicated the elevation of ST-segment disappeared in multiple leads (Fig. 1). However, 3 days after the second PCI, she suffered from MI again (Fig. 1). Coronary angiogram demonstrated long diffuse stenosis in LAD and LCX with TIMI flow 3 (Fig. 2e). IVUS
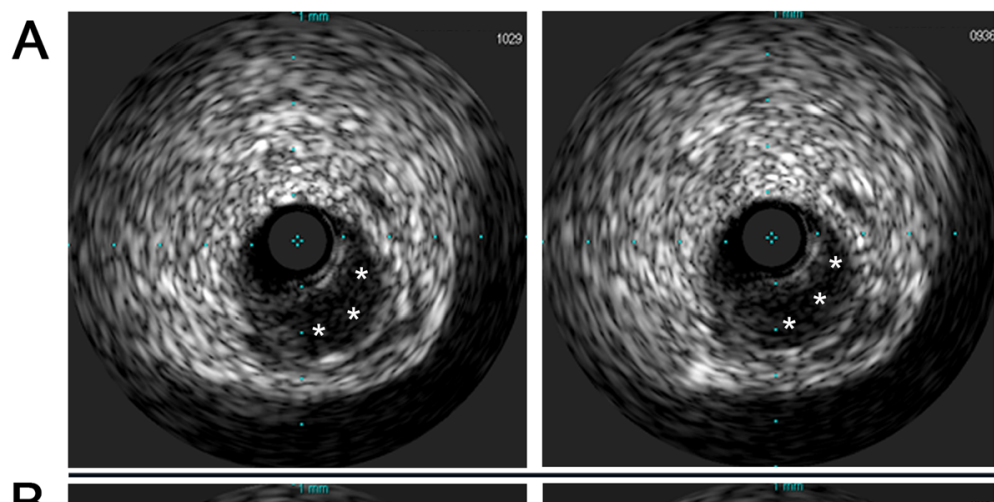

B
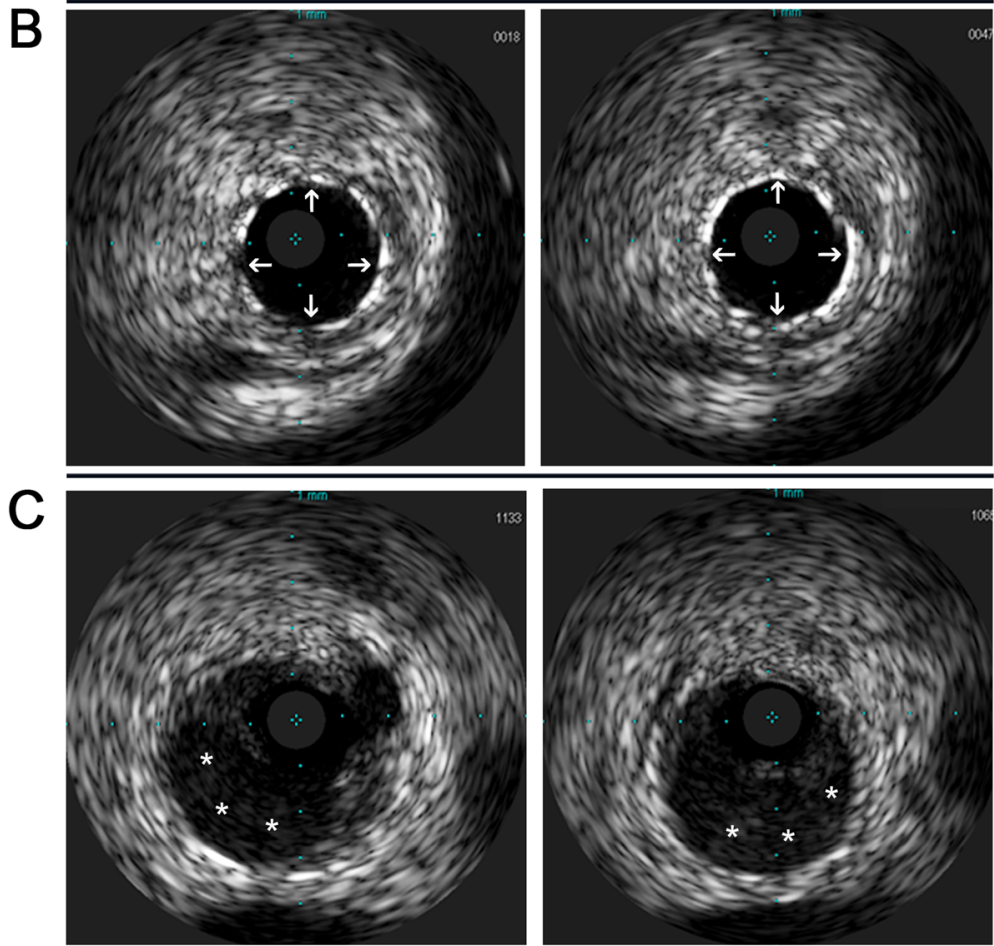

Fig. 3 a Intravascular ultrasound (IVUS) images were presented to show the artery dissection starting from the proximal right coronary artery and ascertained the guidewire passed through the true lumen properly (left and right). b IVUS demonstrated stents attached to endothelium well and covered artery dissections completely (left and right). c IVUS showed multiple focal artery dissections located at LMC, LAD, as well as the ostium and the proximal segment of LCX (left and right). The intramural hematoma was demonstrated $\left({ }^{*}\right)$, and implanted stents were indicated with arrows 
showed that multiple artery dissections located in midto-distal segments of the left main coronary artery (LMC), LAD, as well as the ostium and proximal segment of LCX (Fig. 3c, left and right). We decided to intervene in the LMC, LAD, and LCX arteries by stent implantation. Multiple drug-eluting stents were positioned and implanted into focal lesions of LAD, LCX, and LMC arteries to seal intimal tears. The optimal results of no residual stenosis and restoration of TIMI 3 flow in coronary arteries were achieved (Fig. 2f). During the following week, antiplatelet and antithrombotic therapies were continued for this patient. She had no more chest pain. The hs-troponin I progressively reduced to $0.24 \mathrm{ng} / \mathrm{mL}$. The echocardiography showed slightly decreased systolic function $(\mathrm{EF}=57 \%)$, normal diastolic function, but unsynchronized ventricular wall motion. She recovered well and then was discharged home. One month after discharge, follow-up at the outpatient department showed she had no chest discomfort.

\section{Genomic analysis}

Her father died at the age of 55 years due to MI. Her paternal aunt also suffered from MI and died 3 days after child delivery. It does appear that a heritable disorder was present in her family. In order to find potentially causative gene variants, we performed the whole-exome sequencing (WES) using genomic DNA isolated from the peripheral blood of this patient. The WES was done on MGISEQ-200 Sequencer (MGI Tech Co., Limited, China). The WES achieved an average coverage of $\geq 100$ $\mathrm{X}$ on target and $95 \%$ of bases covered at $\geq 20 \mathrm{X}$. We screened for rare variants with a MAF of $<0.01$ (PM2: Extremely low frequency, ACMG guideline) based on the databases of the 1000 Genomes project and ESP 6500 . We further validated variants by Sanger sequencing. Sequence alternations were reported according to Human Genome Variation Society guidelines (HGVS) and mapped to Human Genome Build GRCh37/UCSC hg19(https://genome.ucsc.edu/cgi-bin/hgGateway?db=

hg19). It is noteworthy that no well-known pathological variants (e.g., TSR1, FBN1, ACTA2, SMAD3, COL3A1, $T G F B R 1 / R 2$ ) were found in this patient, whereas we identified a novel heterozygous missense variant, c.4574 C > T (p.Arg1438Cys), in the NOTCH1 gene (https:// www.ncbi.nlm.nih.gov/gene/?term=NM_017617.5)

(Fig. 4a). Importantly, this missense mutation was not found in the non-SCAD cohort controls of China [8]. It is a quite rare variant with the dbSNP allele frequency of $9.023 \mathrm{e}^{-6}$. The residue is located very close to the NL domain (Domain found in Notch and Lin-12, amino acid: 1442-1479) of neurogenic locus notch homolog protein 1 preproprotein (https://www.ncbi.nlm.nih.gov/protein/ NP_060087.3) (Fig. 4b). It is a conserved residue among species, including human, chimpanzee, monkey, mouse, and rat (Fig. 4c). The structure models of wildtype (WT) and mutant (Mut) protein were built using SWISSMODEL (https://www.swissmodel.expasy.org). It appears that the substituted cysteine did not apparently change the senior structure of the variant protein (Fig. 4d). Then, the in-silico software of the computational algorithms SIFT (Sorting Intolerant from Tolerant, http:// sift.jcvi.org), PolyPhen2 (Polymorphism Phenotyping, http://genetics.bwh.harvard.edu/pph.harvard.edu/pph22) and Mutation Taster (http://www.mutationtaster.org) were used to predict the pathogenicity of this novel variant. While SIFT suggested it as being a tolerated variant, PolyPhen2 and Mutation Taster prediction tools presented it as being potentially damaging or diseasecausing variant, respectively (PP3: Multiple lines of computational evidence support a deleterious effect on the gene or gene product, ACMG guideline).

\section{Discussion and conclusions}

In terms of therapeutic strategies for SCAD, conservative management and PCI have been well acknowledged. However, the decisions should be individualized and contemplated in the context of the coronary anatomy, the stability of vessel dissection, ongoing ischemia, and hemodynamic conditions $[5,6]$. Considering the patient had the hemodynamic stability with TIMI3 flow in the culprit artery, we initially preferred the minimalist mechanical intervention by undersized balloons at low-pressure dilatation. We did not continue with a more revascularization strategy to allow the chance of "healing" of suspicious SCAD lesions to occur. Unfortunately, this case is quite rare because the SCAD with MI reoccurred within a short period. Therefore we adopted optimized PCI approaches to improve the outcomes of revascularization and avoid potential risks for PCI-associated complications [12, 13]. First, we performed coronary angiography with femoral access to reduce the risk of catheter-induced iatrogenic dissection. Owing to the complex upper limb vessel anatomy, the catheter-induced injuries were frequently reported in SCAD patients when radial access was used [14]. Second, we used IVUS to aid the diagnosis of SCAD, which was also helpful for us to ascertain the guidewire passed through the true lumen properly, a critical step when revascularization procedures were pursued. Third, the multiple drugeluting stents were sequentially implanted to target and seal focal dissections of coronary arteries. The patient had successful procedural outcomes.

This patient showed a susceptive family history of an inherited systematic arteriopathy. Therefore, we were motivated to explore the potential genetic variants further. We performed WES and Sanger sequencing on the 


\section{A}

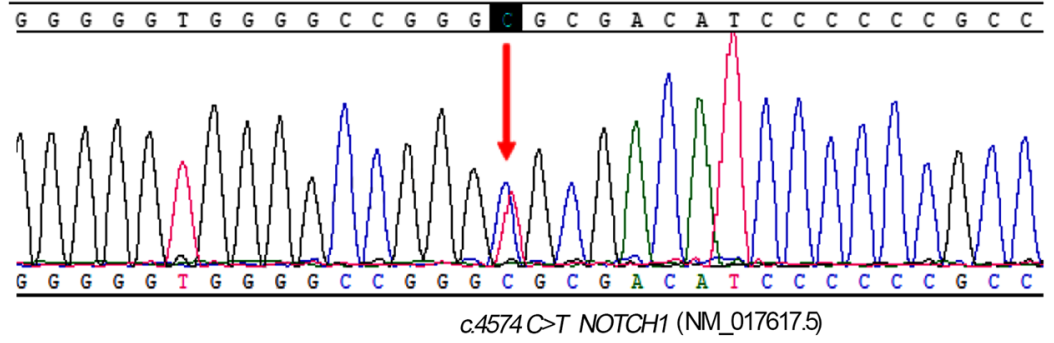

B

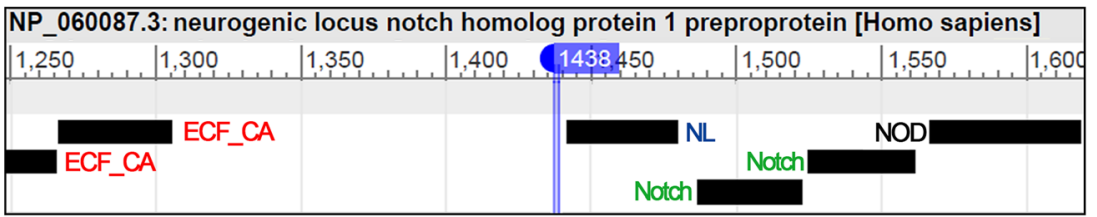

C

NGLLCHILDYSFGGGAGRDIPPPLIEEACE Human
NGLLCHILPYSFGGGAGRDIPPPLLEEACE Pan paniscus
NGLLCHILDYSFGGGAGRDIPPPLIEEACE G. gorilla
NGLLCHILDYSFGGGAGRDPPPQIEEACE M. mulatta
NGLLCHILDYSFTGGAGRDIPPPQIEEACE M. musculus
NGLLCHILDYSFTGGAGRDIPPPQIEEACE R. norvegicus

D

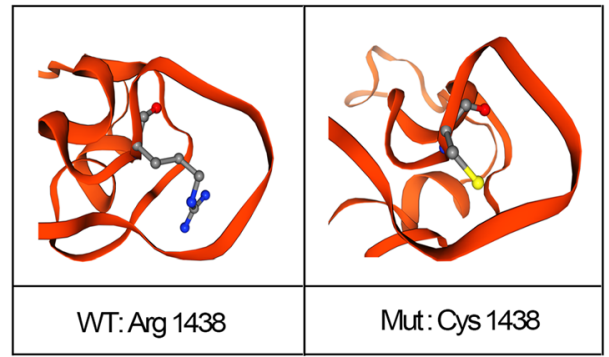

Fig. 4 a Sanger sequencing confirmed that the patient was heterozygous for NOTCH1 c.4574 C > T (p.Arg1438Cys) variant. b A schematic diagram of the domain regions of neurogenic locus notch homolog protein 1 preproprotein (NP_060087.3, amino acid:1250 to 1600). The mutant residue was located very close to the NL domain. EGF_CA: Calcium-binding EGF-like domain; NL: Domain found in Notch and Lin-12; Notch: Lin12/Notch repeat; NOD: NOTCH domain. c The protein sequence alignment showed the variant region was conserved among species. $\mathbf{d}$ The structure modeling of wildtype (WT) and mutant (Mut) Notch1 was built using SWISSMODEL

index patient and, for the first time, reported a novel heterozygous $\mathrm{NOTCH} 1$ variant that has never been documented in the medical literature. NOTCH1 encodes a large protein containing an extracellular domain with epidermal growth factor (EGF)-like repeats, cysteine-rich Notch/LIN-12 repeats, an intracellular domain with ankyrin repeats, and a transmembrane domain. The Notch signaling pathway is highly conserved across species. Binding of the Notch receptor ligands, Jagged or Deltalike, leads to enzymatic cleavage and nuclear translocation of the Notch intracellular domain (NICD). NICD binds to DNA-binding protein CSL, leading to transcriptional activation of downstream target genes (e.g., Hes and $\mathrm{Hey}$ ) and cell fate determination [15]. Notch1 signaling plays a crucial role in vascular smooth muscle cell (VSMC) apoptosis. The defective Notch1 signaling potentiates the changes in VSMC apoptosis and proliferation [16]. VSMC-specific Notch-1 heterozygous deficient mice showed decreased VSMC proliferation but increased cell apoptosis [17]. Notch1 is also critical to coordinate VSMC-endothelial cell contact and maintain monolayer integrity and vascular homeostasis in response to injury [18]. Mutations in NOTCH1 (e.g., p.Thr596Met, p.Arg1108X, p.Ala1343Val, p.Pro1390Thr, p.His1505 del, p.Pro1797His) are implicated in bicuspid aortic valve aortopathy, a condition associated with abnormal apoptosis and differentiation of VSMCs [19-21]. Yet, a pathophysiological association between NOTCH1 mutation and artery dissections has not been well established. A case study reported that patients carrying NOTCH1 mutation (p.Pro2122Leu) showed spontaneous and recurrent dissections of extracranial arteries [22]. A recent Chinese SCAD cohort study identified 27 NOTCH1 variants, but most of them also occur in nonSCAD controls. There are two variants specifically identified in SCAD cases. The prediction tools presented 
them as being tolerated (p.Asp1277Asn) and damaging (p.Glu1143Gly), respectively [8]. Of note, the p.Arg1438Cys variant was neither found in these nonSCAD controls. Although this variant has an extremely low frequency $(\mathrm{MAF}<0.01)$, we are not able to validate this variant in her mother to provide PS2 evidence and further conclude it as a likely pathogenic variant (ACMG guideline). This variant is classified as disease-causing by in silico prediction. However, structural modeling did not find an apparent change in the senior structure. Therefore, the evidence to conclude its potential pathogenicity remains insufficient. We are currently examining the ligand binding and Notch1-dependent differentiation of VSMC after transfection with variant. It is of significant interest to investigate the pathophysiological association between this missense mutation and vessel fragility via more detailed experiments.

In conclusion, we describe a rare case of recurrent SCAD in a young woman after baby delivery. The initial conservative management and then IVUS-guided PCI achieved optimal results of revascularization in affected coronary arteries. We, for the first time, identified a novel missense variant in the NOTCH1 gene, which appears to be a potential predisposing factor for artery fragility.

\section{Abbreviations \\ ECG: Electrocardiogram; EGF: Epidermal growth factor; IMH: Intramural hematoma; IVUS: Intravascular ultrasound; LAD: Left anterior descending coronary artery; LCX: Left circumflex artery; LMC: Left main coronary artery; MI: Myocardial infarction; PCl: Primary percutaneous coronary intervention; RCA: Right coronary artery; SCAD: Spontaneous coronary artery dissection; STEMI: ST-elevation myocardial infarction; TIMI: Thrombolysis in myocardial infarction; VSMC: Vascular smooth muscle cell; WES: Whole-exome sequencing}

\section{Acknowledgments}

The authors sincerely thank the patient's collaboration.

\section{Authors' contributions}

$B B, M Z$, and $H C$ interpreted the patient data, analyzed the gene sequencing data, and drafted this manuscript. $Y Z, J Z$, and WL performed the percutaneous coronary intervention and revised the manuscript. WM performed and analyzed intravascular ultrasound images and contributed to the writing of the draft. All authors approved the manuscript for submission.

\section{Funding}

This work was supported by the Seed Funding for Young Individual Research of Shenzhen Second People's Hospital (4001019). The funding bodies played no role in the design of the study and collection, analysis, and interpretation of data and writing the manuscript.

\section{Availability of data and materials}

The data used and analyzed in the present report were deposited in the NCBI Sequence Read Archive (SRA) database. The data are accessible via the SRA accession: PRJNA610829.

\section{Ethics approval and consent to participate}

The study was conducted according to the International Standards of Good Clinical Practice (ICH guidelines and the Declaration of Helsinki). The report was approved by the local Research Ethics Committees of the Shenzhen Second People's Hospital, Shenzhen, China.

\section{Consent for publication}

All authors declared the patient has signed written informed consent for publication of clinical, radiological, and biological data.

\section{Competing interests}

All authors have declared that they have no conflict of interest to disclose.

Received: 22 December 2019 Accepted: 24 May 2020

Published online: 01 June 2020

\section{References}

1. Saw J, Mancini GBJ, Humphries KH. Contemporary review on spontaneous coronary artery dissection. J Am Coll Cardiol. 2016;68(3):297-312.

2. Faden MS, Bottega N, Benjamin A, Brown RN. A nationwide evaluation of spontaneous coronary artery dissection in pregnancy and the puerperium. Heart. 2016:102(24):1974-9.

3. Elkayam U, Jalnapurkar S, Barakkat MN, Khatri N, Kealey AJ, Mehra A, Roth A. Pregnancy-associated acute myocardial infarction: a review of contemporary experience in 150 cases between 2006 and 2011. Circulation. 2014;129(16): 1695-702.

4. Tweet MS, Hayes SN, Codsi E, Gulati R, Rose CH, Best PJM. Spontaneous coronary artery dissection associated with pregnancy. J Am Coll Cardiol. 2017;70(4):426-35.

5. Adlam D, Alfonso F, Maas A, Vrints C, Writing C. European Society of Cardiology, acute cardiovascular care association, SCAD study group: a position paper on spontaneous coronary artery dissection. Eur Heart J. 2018; 39(36):3353-68.

6. Hayes SN, Kim ESH, Saw J, Adlam D, Arslanian-Engoren C, Economy KE, Ganesh SK, Gulati R, Lindsay ME, Mieres JH, et al. Spontaneous coronary artery dissection: current state of the science: a scientific statement from the American Heart Association. Circulation. 2018;137(19):e523-e57.

7. Vandeloo B, Azzano A, Schoors D, Verstraeten A, Van Laer L, Loeys B, Vermeersch P. Spontaneous coronary artery dissection in a man with a novel missense mutation in SMAD2 treated by optical coherence tomography-guided percutaneous coronary intervention. JACC CardiovasC Interv. 2019:12(6):e45-e7.

8. Sun Y, Chen Y, Li Y, Li Z, Li C, Yu T, Xiao L, Yu B, Zhao H, Tao M, et al. Association of TSR1 variants and spontaneous coronary artery dissection. J Am Coll Cardiol. 2019;74(2):167-76

9. Henkin S, Negrotto SM, Tweet MS, Kirmani S, Deyle DR, Gulati R, Olson TM, Hayes SN. Spontaneous coronary artery dissection and its association with heritable connective tissue disorders. Heart. 2016:102(11):876-81.

10. de Winter RJ, Verouden NJ, Wellens HJ, Wilde AA. Interventional cardiology Group of the Academic Medical C. a new ECG sign of proximal LAD occlusion. N Engl J Med. 2008;359(19):2071-3.

11. Wimalaratna HS. "Tombstoning" of ST segment in acute myocardial infarction. Lancet. 1993;342(8869):496.

12. Tweet MS, Eleid MF, Best PJ, Lennon RJ, Lerman A, Rihal CS, Holmes DR Jr, Hayes SN, Gulati R. Spontaneous coronary artery dissection: revascularization versus conservative therapy. Circ Cardiovasc Interv. 2014;7(6):777-86.

13. Buja P, Coccato M, Fraccaro C, Tarantini G, Isabella G, Almamary A, Dariol G, Panfili M, lliceto S, Napodano M. Management and outcome of spontaneous coronary artery dissection: conservative therapy versus revascularization. Int J Cardiol. 2013;168(3):2907-8.

14. Prakash R, Starovoytov A, Heydari M, Mancini GB, Saw J. Catheter-induced iatrogenic coronary artery dissection in patients with spontaneous coronary artery dissection. JACC Cardiovasc Interv. 2016:9(17):1851-3.

15. Artavanis-Tsakonas $S$, Rand MD, Lake RJ. Notch signaling: cell fate control and signal integration in development. Science. 1999;284(5415):770-6.

16. Morrow D, Sweeney C, Birney YA, Cummins PM, Walls D, Redmond EM, Cahill PA. Cyclic strain inhibits notch receptor signaling in vascular smooth muscle cells in vitro. Circ Res. 2005;96(5):567-75.

17. Li Y, Takeshita K, Liu PY, Satoh M, Oyama N, Mukai Y, Chin MT, Krebs L, Kotlikoff MI, Radtke F, et al. Smooth muscle Notch1 mediates neointimal formation after vascular injury. Circulation. 2009;119(20):2686-92.

18. Miyagawa K, Shi M, Chen PI, Hennigs JK, Zhao Z, Wang M, Li CG, Saito T, Taylor S, Sa S, et al. Smooth muscle contact drives endothelial regeneration by BMPR2-Notch1-mediated metabolic and epigenetic changes. Circ Res. 2019;124(2):211-24. 
19. Garg V, Muth AN, Ransom JF, Schluterman MK, Barnes R, King IN, Grossfeld PD, Srivastava D. Mutations in NOTCH1 cause aortic valve disease. Nature. 2005;437(7056):270-4.

20. Mohamed SA, Aherrahrou Z, Liptau H, Erasmi AW, Hagemann C, Wrobel S, Borzym K, Schunkert H, Sievers HH, Erdmann J. Novel missense mutations (p.T596M and p.P1797H) in NOTCH1 in patients with bicuspid aortic valve. Biochem Biophys Res Commun. 2006;345(4):1460-5.

21. McKellar SH, Tester DJ, Yagubyan M, Majumdar R, Ackerman MJ, Sundt TM 3rd. Novel NOTCH1 mutations in patients with bicuspid aortic valve disease and thoracic aortic aneurysms. J Thorac Cardiovasc Surg. 2007;134(2):290-6.

22. Guevara C, Farias G, Bulatova K, Alarcon P, Soruco W, Robles C, Morales M. NOTCH 1 mutation in a patient with spontaneous and recurrent dissections of extracranial arteries. Front Neurol. 2017;8:245.

\section{Publisher's Note}

Springer Nature remains neutral with regard to jurisdictional claims in published maps and institutional affiliations.

Ready to submit your research? Choose BMC and benefit from:

- fast, convenient online submission

- thorough peer review by experienced researchers in your field

- rapid publication on acceptance

- support for research data, including large and complex data types

- gold Open Access which fosters wider collaboration and increased citations

- maximum visibility for your research: over $100 \mathrm{M}$ website views per year

At BMC, research is always in progress.

Learn more biomedcentral.com/submissions 